\title{
Additively manufactured high-performance polymeric materials and their potential use in the oil and gas industry
}

\author{
Eugene B. Caldona, Department of Chemical and Biomolecular Engineering and Institute for Advanced Materials and Manufacturing, University of Tennessee, \\ Knoxville, TN 37996, USA \\ John Ryan C. Dizon, Design, Research, Extension in Additive Manufacturing, Advanced Materials and Advanced Manufacturing (DR3AM) Center, Office \\ of Environmental Sustainability (OES), and Department of Industrial Engineering, Bataan Peninsula State University, 2100 City of Balanga, Bataan, Philippines \\ Robert Andrew Viers, Department of Chemical and Biomolecular Engineering and Institute for Advanced Materials and Manufacturing, University of Tennessee, \\ Knoxville, TN 37996, USA \\ Vincent Joseph Garcia, Department of Mining, Metallurgical, and Materials Engineering, University of the Philippines Diliman, 1101 Quezon City, Philippines; \\ Department of Macromolecular Science and Engineering, Case Western Reserve University, Cleveland, OH 44106, USA \\ Zane J. Smith, Department of Chemical and Biomolecular Engineering and Institute for Advanced Materials and Manufacturing, University of Tennessee, Knoxville, \\ TN 37996, USA; Department of Materials Science and Engineering, University of Tennessee, Knoxville, TN 37996, USA \\ Rigoberto C. Advincula $(\mathbb{D}$, Department of Chemical and Biomolecular Engineering and Institute for Advanced Materials and Manufacturing, University \\ of Tennessee, Knoxville, TN 37996, USA; Department of Macromolecular Science and Engineering, Case Western Reserve University, Cleveland, OH 44106, USA; \\ Department of Materials Science and Engineering, University of Tennessee, Knoxville, TN 37996, USA; Center for Nanophase Materials and Sciences, Oak Ridge National \\ Laboratory, Oak Ridge, TN 37830, USA \\ Address all correspondence to Rigoberto C. Advincula at radvincu@utk.edu
}

Rigoberto C. Advincula was an editor of this journal during the review and decision stage. For the MRS Communications policy on review and publication of manuscripts authored by editors, please refer to http://www.mrs.org/editor-manuscripts/

(Received 31 August 2021; accepted 10 November 2021; published online: 16 December 2021)

\section{Abstract}

The oil and gas industry has been tagged as among the largest revenue-generating sectors in the world. High-performance polymers (HPPs), on the other hand, are among the most useful industrial materials, while the utility of 3D printing technologies has evolved and transitioned from rapid prototyping of composite materials to manufacturing of functional parts. In this prospective, we highlight the potential uses and industrial applications of 3D-printed HPP materials in the oil and gas sector, including the challenges and opportunities present.

\section{Introduction}

Oil and gas companies are among the biggest and most important industrial sectors in the world, with crude oil and natural gas prices as two of the most closely watched in the global market. ${ }^{[1]}$ It plays a crucial role in the global economy as it not only generates a revenue of roughly US\$ 3 trillion annually worldwide, ${ }^{[2]}$ but is also capable of globally fulfilling the growing energy needs throughout the next decades. ${ }^{[1]}$ However, the production and distribution of oil and gas products involve a tedious process and complex system, which are labor- and capital-intensive. For instance, upstream exploration, which involves finding reservoirs and drilling wells, requires the use of state-of-the-art technologies and materials that are noncorrosive, chemical resistant, and highly thermo-mechanically stable. ${ }^{[3]}$ Likewise, tools, equipment, and instruments required for downhole operations are expected to satisfactorily perform under harsh environments and high-pressure and hightemperature conditions. ${ }^{[3]}$ While majority of these are made of highly corrosion resistant metallic materials, a good number of their components or parts are made of polymeric-based materials such as polymer nanocomposites, blends, reformulated elastomers, and high-performance polymers (HPPs). ${ }^{[3-5]}$ Because of their strength-to-weight ratios, ability to withstand a broader range of chemical, thermal, and physical stress, and other advantages over metallic materials, HPPs have become an attractive choice for utility across a wide range of demanding applications. ${ }^{[4]}$ In addition to their appealing properties, HPPs also display high dimensional stability and design flexibility such that they can be easily molded to different shapes and complex geometries to continuously fulfill the demand for safety features, functional integration, and miniaturization, leading to their industrial application, not only in the automotive, aerospace, marine, and biomedical, but also in the oil and gas. ${ }^{[4,6]}$

The time to delivery of essential tools and equipment is crucial to achieve dynamic industrial process operations in 
the oil and gas. Additive manufacturing (AM, or 3D printing) is a promising approach to fabricating and delivering, in a timely fashion, the required tools, components, and other replacement parts for a smooth industrial operation. AM processes can offer onsite services, where spare parts can be easily $3 \mathrm{D}$-printed and replaced on demand, leading to significant profits in terms of inventory management, manufacturing lead time, productivity, materials transportation, asset uptime, and supply chain management. ${ }^{[7,8]}$ Easy access to $3 \mathrm{D}$ printers on board ships and offshore oil platforms can provide instant additively manufactured auxiliary parts needed for machines and equipment located in remote areas or where delivery is impractical. ${ }^{[7,9]}$ As HPPs are among the most useful AM materials for oil and gas applications, the development and utility of AM techniques can transform the inherent characteristics of HPPs into a wide variety of promising functional structures.

Our group has published several review papers on 3D printing of hydrogels for tissue engineering, ${ }^{[10]}$ viscoelastic materials for composite and food fabrication, ${ }^{[11]}$ membrane materials for carbon capture and water treatment, ${ }^{[12,13]}$ useful devices and materials for COVID-19, ${ }^{[14]}$ thermoplastic polymer composites and nanocomposites, ${ }^{[15]}$ and polymers for biomedical applications, ${ }^{[16]}$ mechanical characterization, ${ }^{[17]}$ and electronics. ${ }^{[18]}$ In this current prospective, we aim to highlight the promising use of 3D-printed HPPs in the oil and gas industry. Although HPPs and 3D printing technologies have been widely reported in the literature, the majority of the past and current reviews, in general, have concentrated individually on their utility in different industrial settings. Thus, this work is an effort to explore in one prospective paper, not only the promising applications, but also the challenges and opportunities in using additively manufactured HPPs in the oil and gas industry.

\section{Overview of high performance polymers \\ Methods of polymer classification}

Significant improvements to polymeric materials through evolutions in synthetic and processing techniques initiated the need to precisely differentiate materials based on their physical properties. Generally, when polymers are classified according to their physical properties, they are referred to as commodity, engineering, or high performance polymers (HPPs). Commodity polymers are inexpensive to manufacture, but demonstrate low thermal and mechanical properties, compared to engineering and high performance polymers. Engineering polymers exhibit improved thermal and mechanical properties relative to commodity polymers, while maintaining reasonable processing costs, but demonstrating lower thermal and mechanical performance compared to HPPs. HPPs display the best thermal and mechanical properties of the three, but have increased manufacturing cost and reduced processability. Certain polymers have also even been classified as ultra-performance polymers owing to their thermal and mechanical properties being even superior

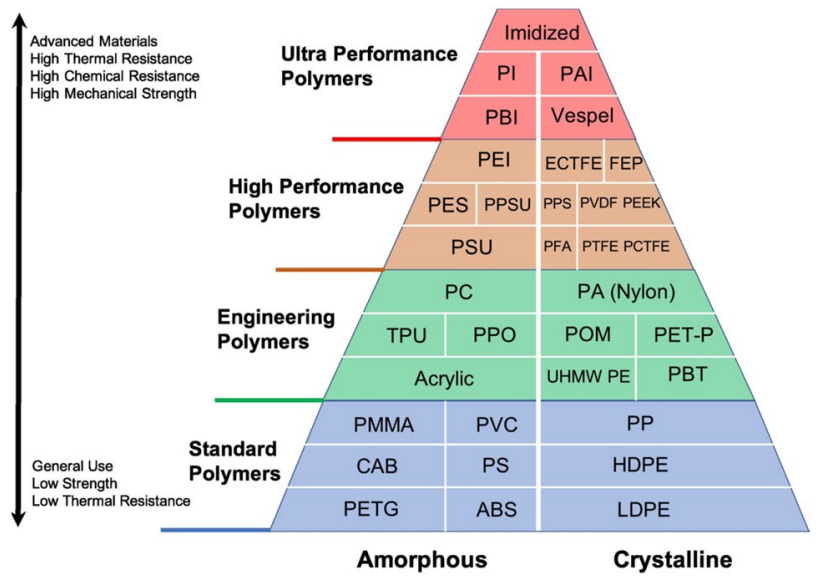

Figure 1. Organization of polymers according to their chemical and thermomechanical properties. ${ }^{[4]}$ Reprinted (adapted) from Ref. 4 with permission from Elsevier.

to that of traditional HPPs. ${ }^{[4]}$ Fig. 1 illustrates the progression of these polymeric materials (with examples from each class) as a function of their thermomechanical properties. This section discusses the various criteria and features of HPPs and lists some examples of common HPPs with potential AM applications in the oil and gas industry.

As shown in Fig. 1, polymers can be further divided into the subcategories of amorphous and crystalline, according to their morphology. Amorphous polymers are composed of macromolecular chains with random orientations throughout the polymer matrix. They display only a glass transition temperature $\left(T_{\mathrm{g}}\right)$, but with no definite melting temperature $\left(T_{\mathrm{m}}\right)$. Conversely, crystalline (or semi-crystalline) polymers contain regions of highly ordered or packed molecular chains and demonstrate both a $T_{\mathrm{g}}$ and $T_{\mathrm{m}}$. This packing can occur when polymer chains have the appropriate geometries and intermolecular attractions to achieve a thermodynamically favorable alignment.

\section{Advantages of using HPPs}

HPPs are characterized by their exceptional mechanical integrity, thermal stability, and chemical resistivity. More specifically, HPPs are capable of retaining their mechanical properties upon exposure to extreme thermal and/or chemical environments. The mechanical properties of interest vary depending on the application, but usually involve the following: hardness, tensile strength, toughness, tribological integrity, and dimensional stability. Exact criteria for HPPs have been developed and are listed as follows: ${ }^{[19]}$

- Retention of structural integrity upon exposure to $177^{\circ} \mathrm{C}$ for $>10,000 \mathrm{~h}$ in the presence of mechanical stress (short and long term), harsh chemicals, and electrical shock.

- Minimum thermal decomposition temperature of $450^{\circ} \mathrm{C}$ (i.e., $5 \%$ weight loss at $450^{\circ} \mathrm{C}$ ).

- Minimum temperature of $177^{\circ} \mathrm{C}$ at which $10 \%$ deflection occurs on a sample under a load of 1.52 MPa. 
- Highly aromatic polymers with rigid regions should have high $T_{\mathrm{g}}$ values $\left(>200^{\circ} \mathrm{C}\right)$ and superior mechanical properties.

Various molecular scale features contribute to achieving polymers displaying mechanical and thermal properties in the high performance regime. HPPs typically exploit some combination of molecular features. Increased primary bond dissociation energy (BDE) is associated with improved thermal stability and chemical resistivity. ${ }^{[19]}$ For example, chemically inert and thermally stable fluoropolymers such as polyvinylidene fluoride (PVDF) and polytetrafluoroethylene (PTFE) are largely composed of $\mathrm{C}-\mathrm{F}$ bonds having a BDE of $123 \mathrm{kcal} \mathrm{mol}^{-1}$, whereas the $\mathrm{BDE}$ of a C-H bond is $83 \mathrm{kcal} \mathrm{mol}^{-1} \cdot{ }^{[4]}$ Architectures consisting of high aromatic content in the polymer backbone (polyaromatics) have become an exceedingly popular class of HPPs due to the exceptional mechanical properties (e.g., stiffness, tensile strength, hardness, etc.) coupled with thermal stability and chemical resistivity. The aromatic groups, not only possess the benefit of high primary BDE $\left(145 \mathrm{kcal} \mathrm{mol}^{-1}\right.$ for $\mathrm{C}=\mathrm{C}$ bond), but they also provide resonance stabilization, which can range from $40-70 \mathrm{kcal} \mathrm{mol}^{-1} .{ }^{[4]}$ The molecular rigidity of the aromatic groups also contributes to the macroscopic stiffness and strength observed in the mechanical properties. Other features that enhance polymer performance include molecular weight (high with narrow distribution), uniform structure for better packing (crystallinity), intermolecular forces (hydrogen bonding), crosslinking, and presence of additives (fibers, nanoparticles, etc.). ${ }^{[19]}$ Given these advantages, HPPs are highly recommended for use in applications involving harsh environments such as those encountered in the oil and gas industry.

\section{Commonly used HPPs}

\section{Polyphenylene sulfide}

Polyphenylene sulfide (PPS, trade name Ryton) is a semi-crystalline high performance thermoplastic polymer composed of benzene rings connected by sulfur atoms at the para position. The $T_{\mathrm{g}}$ of PPS is relatively low for HPPs at $85^{\circ} \mathrm{C}$, while the $T_{\mathrm{m}}$ is $285^{\circ} \mathrm{C}^{[20]} \mathrm{PPS}$ has been investigated for a wide variety of applications since it was first introduced in the 1960s. Special attention has been paid to PPS for coating applications owing to its excellent resistance to corrosion and other chemicals including organic solvents, inorganic salts, bleaches, and strong bases ${ }^{[4]}$ Moreover, PPS is totally insoluble in any known solvent below $200^{\circ} \mathrm{C} \cdot{ }^{[20]}$ PPS also demonstrates a relatively low melt viscosity, albeit at high temperatures, allowing it to be processed by traditional manufacturing methodologies such as injection molding. The melt flow properties of PPS are also compatible with fused deposition modeling (FDM) 3D printing, allowing it to be useful for constructing parts with complex geometries without the need for machining. PPS has also found utility as structural components due to its outstanding hardness and wear resistance, but a susceptibility to warpage and brittleness limits its mechanical applications. ${ }^{[4]}$ For these reasons, extensive work has been done to improve the mechanical performance of PPS. Formulations of PPS containing fillers such as carbon fiber, nylon, and volcanic ash have been developed to improve mechanical properties including its tensile strength and toughness. ${ }^{[4]}$

\section{Polyetherimide}

Polyetherimide (PEI), with a trade name of ULTEM, is an amorphous high performance thermoplastic polymer. PEI has various commercial product lines including ULTEM 9085 and ULTEM 1010 , having $T_{\mathrm{g}}$ values of 186 and $217^{\circ} \mathrm{C}$, respectively. ${ }^{[21,22]} \mathrm{PEI}$ is generally synthesized via a polycondensation reaction between bisphenol A dianhydride and $m$-phenylenediamine. The high aromatic content affords PEI various mechanical properties (e.g., dimensional stability, stiffness, creep resistance, and high strength) that are competitive with metals. Owing to its high $T_{\mathrm{g}}$, PEI can be continuously used for applications requiring temperatures up to $180^{\circ} \mathrm{C}{ }^{[4]}$ PEI also demonstrates desirable safety features such as low smoke emission, flame retardance, and chemical resistivity to alcohols, halogenated solvents, and hydrocarbons. ${ }^{[4]}$ Conversely, PEI requires high processing temperatures, resulting in increased processing costs, but competitively priced filaments are available to be used on FDM 3D printers. Moreover, PEI is prone to warpage during the printing process. Thus, to successfully print PEI, the machine requires a high-temperature nozzle $\left(\sim 400^{\circ} \mathrm{C}\right)$, a heated chamber $\left(90-180^{\circ} \mathrm{C}\right)$, and a heated build plate $\left(120-160^{\circ} \mathrm{C}\right)$. Printing under these conditions, coupled with post process thermal treatments, can reduce the anisotropic properties of the fabricated parts.

\section{Polyethertherketone}

Polyetheretherketone (PEEK), a semi-crystalline thermoplastic, is among the most widely studied and commercially available HPPs. PEEK is composed of a highly aromatic polymer backbone connected by a series of ketone and ether linkages. PEEK has exceptional thermal stability, boasting a $T_{\mathrm{g}}$ of $143^{\circ} \mathrm{C}$ and $T_{\mathrm{m}}$ of $343^{\circ} \mathrm{C} .{ }^{[23]}$ These thermal properties, combined with strong mechanical properties, wear resistance, chemical and corrosion resistance, and hydrolytic stability, have made PEEK an ideal candidate for demanding applications in harsh environments. However, the tradeoff to such properties is realized by increased manufacturing and processing costs. PEEK has been deployed in applications such as pumps, pistons, liners, protective housing components, and medical equipment. PEEK is also compatible with FDM 3D printing methodologies given the appropriate machine. Nozzle temperatures capable of achieving temperatures in excess of $400^{\circ} \mathrm{C}$, along with a heated chamber and build plate, are necessary to print high quality parts with minimal warping and anisotropic properties.

\section{Polyphenylsulfone}

Polyphenylsulfone (PPSU or PPSF), with a trade name of Radel R, is categorized in the amorphous HPP family. PPSU is 
known for its excellent dimensional stability, hydrolytic resistance, inherently flame retardance, and outstanding chemical resistance. Even though PPSU contains a high number of aromatic units, it is fairly easy to melt process due to the biphenylene ether unit, which also contributes to its excellent impact strength and high notched (Izod) impact values. ${ }^{[4]}$ Furthermore, as PPSU is amorphous in nature, it is advantageous over semicrystalline HPPs due to limited shrinkage and warpage. Since PPSU is indeed amorphous, it only displays a $T_{\mathrm{g}}$ of $220^{\circ} \mathrm{C}$, with a maximum working temperature of $160^{\circ} \mathrm{C}^{\left[{ }^{[24]}\right.}$ With PPSU's ease of melt processability, FDM printing of PPSU is fairly simple as long as the accurate printing properties are used. Its excellent hydrolysis and chemical resistance make PPSU ideal for very harsh environmental conditions like in the oil and gas applications (i.e., exposure to steam or seawater at elevated temperatures). Likewise, PPSU also displays high compressive strength and resistance to indentation such that it is capable of withstanding high pressure and harsh conditions.

\section{Fluoropolymers}

Polymers primarily consisting of $\mathrm{C}-\mathrm{F}$ groups are generally known as fluoropolymers. ${ }^{[4]}$ Due to the very high electronegativity of fluorine atoms, fluoropolymers are chemically inert. Thus, they do not commonly react or bond with any other materials. Likewise, their chemical inertness generally makes them water-repellent and nonstick. Furthermore, the $\mathrm{C}-\mathrm{F}$ bond has a high BDE (i.e., $123 \mathrm{kcal} \mathrm{mol}^{-1}$ ), making fluoropolymers highly temperature resistant. ${ }^{[4]}$ Fluoropolymers are semi-crystalline in nature and can be categorized by their degree of fluorination, which defines their thermal stability and chemical inertness. ${ }^{[1]}$ Some common fluoropolymers are PTFE, PVDF, polychlorotrifluoroethylene (PCTFE), and polyvinyl fluoride (PVF). PTFE, also known by its trademark name Teflon, is highly symmetrical, allowing it to be inherently hydrophobic. ${ }^{[25]}$ Teflon is produced by free radical addition polymerization reaction between tetrafluoroethylene monomers. ${ }^{[25]}$ Although PTFE has a $T_{\mathrm{m}}$ and maximum service temperature of 330 and $260^{\circ} \mathrm{C}$, respectively, it is relatively difficult to process as it requires a similar procedure to powder processing through compression molding. ${ }^{[25]}$ In comparison, PVDF, also known as Kynar, is readily processible through standard thermoplastic techniques like extrusion and injection molding. PVDF is synthesized by free radical polymerization of 1,1-diflouroethylene. ${ }^{[26]}$ Furthermore, PVDF is also piezoelectric, especially in its beta crystalline phase, due to its high polarity. PVDF has a $T_{\mathrm{m}}$ of $170^{\circ} \mathrm{C}$ with a maximum service temperature of $150^{\circ} \mathrm{C}^{\left[{ }^{[26]} \text { Since }\right.}$ fluoropolymers have very low friction coefficients and chemical inertness, they are ideal for oil and gas applications (e.g., corrosion protection and anti-wetting coatings). ${ }^{[4,27-30]}$

\section{Overview of AM techniques}

Compared to conventional methodologies such as subtractive and formative manufacturing, AM is a process of combining materials layer upon layer from a model data, creating a $3 \mathrm{D}$ object. ${ }^{[6,17,31,32]} \mathrm{AM}$ is synonymous to the following terminologies: 3D printing, digital manufacturing, freeform fabrication, and rapid prototyping. ${ }^{[6,17]}$ The process usually starts with modeling or scanning the $3 \mathrm{D}$ object, generating a computer-aided design (CAD) model, which is further converted into a stl file that stores only the surface geometry information, but excluding other information like texture or color. In some cases, .obj and .amf file types are also used. The STL file is then processed in a slicing software, where printing resolution, temperature, speed, and infill density are set. The model is sliced into several hundreds or thousands of layers and converted into a G-code that relays all the information to the $3 \mathrm{D}$ printer. With the G-code, the printer can start to fabricate the model layer by layer. After the model is created or printed, the part is removed from the build plate and post-processed for its intended application. ${ }^{[17]}$

Currently, there are many different types of AM technologies available for processing different materials, but requiring different post-processing operations. According to standards, $\mathrm{AM}$ is categorized into seven processes,,${ }^{[6,17,31]}$ which are discussed in the succeeding subsections. These technologies are used depending on the intended applications and requirements. In the following section, common polymer AM technologies, which have potential oil and gas uses, are briefly discussed to provide an overview of their basic operating principles.

\section{Material extrusion}

Material extrusion, also known as fused deposition modeling (FDM) or fused filament fabrication (FFF), is a glue-gun-like process, where each layer is fused on top of (or beside) another layer by melting the material just above its $T_{\mathrm{g}}$, allowing it to flow. The layers are extruded following the pattern provided by the G-code of the model, creating the part in a layer-by-layer fashion. Thermoplastics such as acrylonitrile butadiene (ABS), polyetherimide, polylactic acid (PLA), polycarbonate (PC), and polyethylene terephthalate glycol (PETG) are commonly used. Material extrusion is the most commonly known and used AM technology. ${ }^{[6,13,15,17]}$ Direct ink writing (DIW) is generally classified under this method, but instead of a molten polymer, a thixotropic ink is extruded out of a nozzle under controlled flow rate and applied pressure ${ }^{[18]}$ DIW has recently gained attention from industrial communities due to its cost-effectiveness and ability to print structures on any surface using a wide variety of new composite materials.

\section{Vat photopolymerization}

Stereolithography (SLA) and digital light processing (DLP) are two of the most common technologies under vat photopolymerization. SLA uses a laser to selectively cure (i.e., polymerize) a thin layer of liquid photopolymer resin contained in a reservoir (or vat). On the other hand, in DLP, an image of a layer is flashed (or illuminated) across the entire build plate using a digital projector screen, thereby simultaneously and completely curing the (entire layer of) resin. Typical photocurable resins used are thermosets such as epoxy and acrylate-based formulations usually composed of monomers/oligomers, crosslinkers, and initiators. ${ }^{[6,17,33-35]}$ 


\section{Powder bed fusion}

Powder bed fusion (PBF) uses a high-energy laser source to selectively fuse the powder particles and create the 3D object inside a build area. Selective laser sintering (SLS), which usually uses nylon as its material, is a type of PBF and is used for industrial applications. Nylon parts produced using this method have excellent properties, which are ideal for diverse applications. These materials are also strong and durable especially when used as a matrix material for nanocomposites. ${ }^{[15]}$

\section{Material jetting}

Material jetting (MJ) is similar to inkjet printing (in 2D printers), where photosensitive ink droplets are dispensed by a print head onto a substrate. However, the droplets are deposited on a build plate and immediately UV-cured. Similar to SLA, photopolymers are usually used in this technique. Nanoparticle jetting and drop on demand (DOD) are two other related technologies in this category. Very smooth parts, similar to injection molding, may also be achieved using this technology. Additionally, this technology has multi-color and multi-material capabilities. ${ }^{[6,17]}$

\section{D printing in the oil and gas industry}

A brief discussion on the three distinct market segments of the oil and gas industry could facilitate a better understanding of the potential use of polymer 3D printing. Fig. 2 shows the oil and gas industry supply chain with its segments and corresponding activities. The upstream market, which includes the exploration and production segment, is comprised of the following: exploration, drilling, production, and plug and abandonment. The midstream market, which consists of pipes and transportation methods, is comprised of the following: compressor and pumping stations, geopolitical issue, and maintenance. Additionally, trucking companies, barge companies, and rail service and car providers belong to this segment. Lastly, the downstream market is composed of those relating to the consumers, such as manufacturing, petrochemical refining, retail production distribution, and retail. The upstream and downstream segments are characterized by their heavy investments in infrastructure, equipment, and maintenance. With this segmentation, it is now easier to identify potential use cases for oil and gas applications. ${ }^{[36]}$
For the upstream market, currently, the proven use cases of 3D printing include nozzles for downhole cleanout and subsea injection tools, offshore risers, and gas turbines. However, most of these tools use metallic materials. Speculative use cases include pipeline pigs, sand control screens, linear hanger spikes, drill bits, sliding sleeves (SSD), perforated pup joints, sealing accessories (o-rings and v-packing adapters). ${ }^{[37]}$

Marine pollution, due to oil spills, is a serious environmental concern during oil extraction and transportation. Oil clean-up via oil-water separation technique has therefore gained interests during oily discharges and oil spillage. ${ }^{[38-41]}$ Sorbents made with porous and rough membrane structures can be usually used for oil clean-up. With their high surface area to volume ratio and superhydrophobic/superoleophilic wetting characteristics, sorbents inhibit the passage of water, while allowing the permeation of oil. However, manufacturing these sorbents using conventional methods is relatively complicated and time consuming. It is worth noting that $3 \mathrm{D}$ printing has been reportedly used for fabricating porous membrane structures ideal for oil/water separation. ${ }^{[13]}$ Table I and Figs. 3 and 4 provide some examples of 3D-printed membranes and sorbents for such application.

3D-printed polymers have several industrial oil and gas use cases. Pellejero et al. ${ }^{[52]}$ reported the use of functionalized 3D-printed ABS filters for the capture of toxic gas. Chang et al. ${ }^{[53]} 3 \mathrm{D}$-printed a porous polyimide for oil impregnation. Castiblanco et al. ${ }^{[54]}$ used PETG to 3D-print a microfluidic device, which was used for petroleomic studies. Osei-Bonsu et al. ${ }^{[55]}$ reported a foam flow using a 3D-printed porous medium. Oo et al. ${ }^{[56]} 3 \mathrm{D}$-printed a rotor-stator reactor for producing biodiesel from free fatty acid (FFA)-rich oils. Furthermore, Jacobs $^{[57]}$ reported the use of a HPP polyether ether ketone (PEEK) in fabricating a hydraulic line for subsea well stimulation and acid treatments. Table II summarizes these use cases.

\section{The potential of HPPs in the oil and gas industry}

Over the years, there has been an increase in research interest on HPPs and their composites due to their extremely significant impact to various applications in aerospace, marine, automotive, biomedical, and energy among others. However, even with the superior properties that these materials offer, researchers are

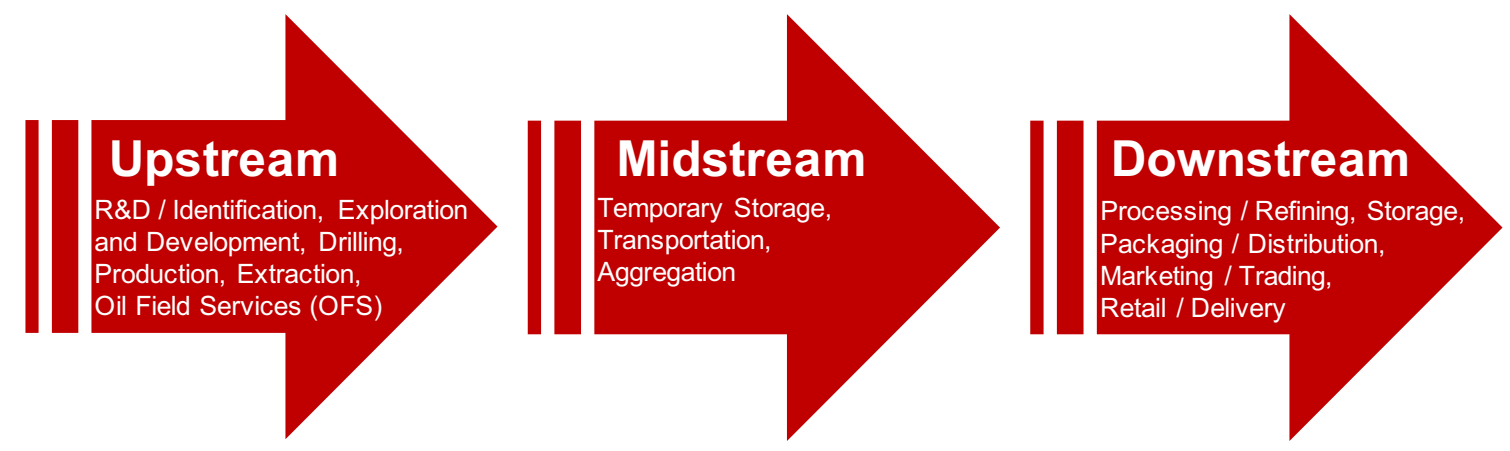

Figure 2. Oil and gas supply chain and its industrial segments and corresponding activities. 


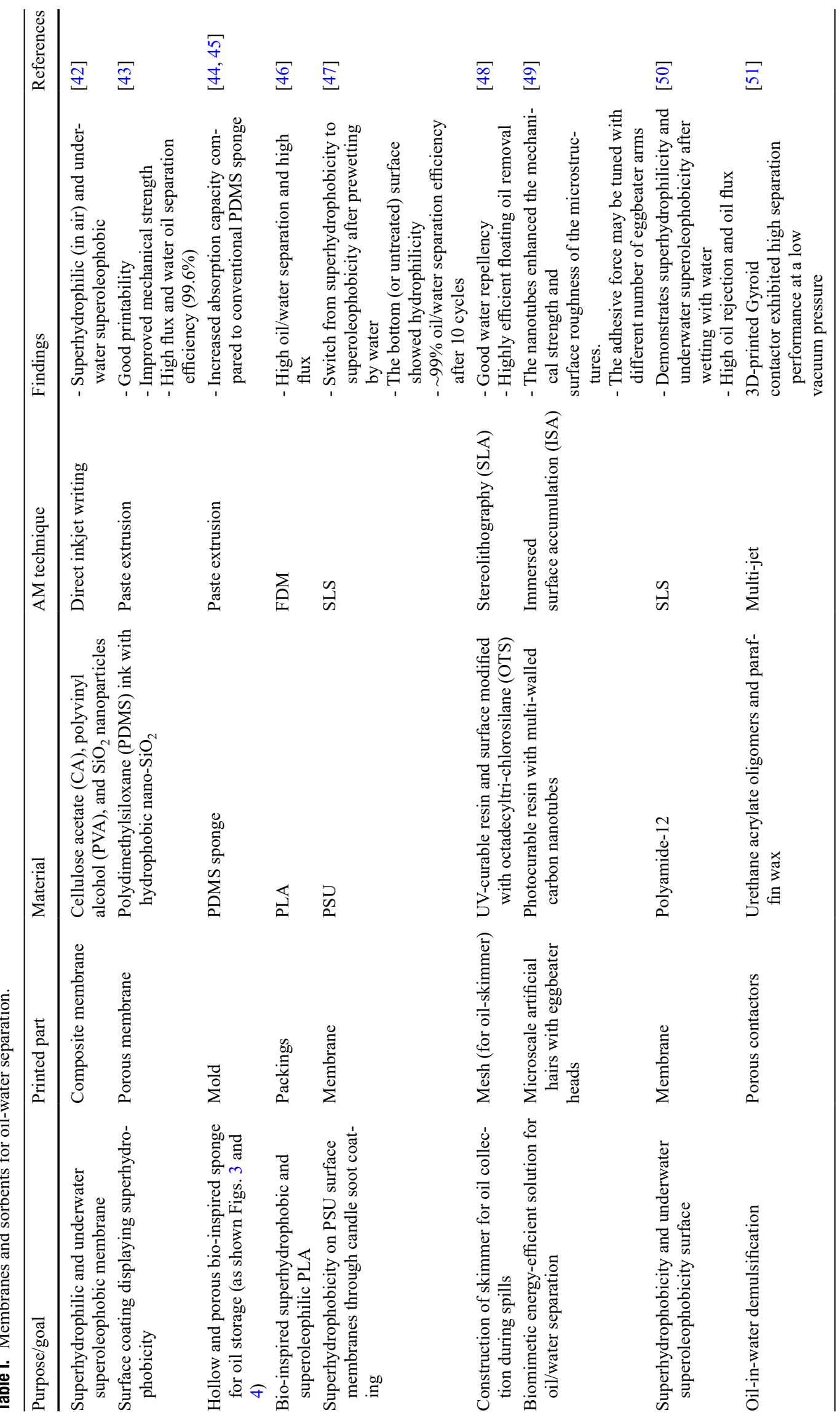




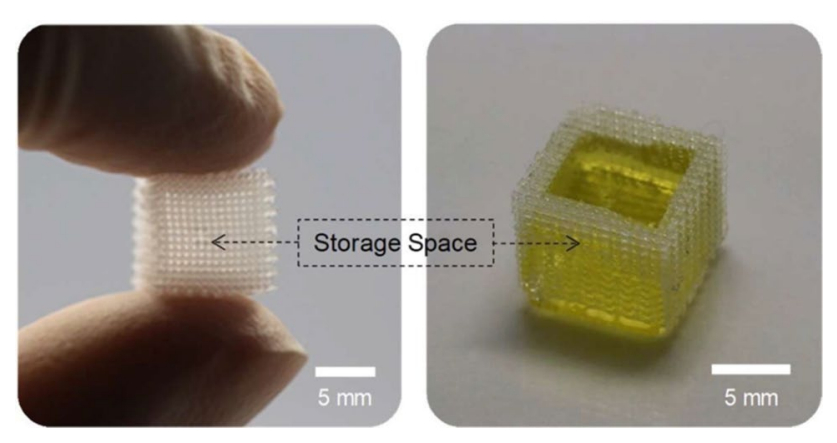

Figure 3. Visual images showing the storage space and oil absorption capability of printed PDMS sponge. ${ }^{[44,45]}$ Reprinted (adapted) from Ref. 44 with permission from Elsevier.

still looking for ways to overcome challenges and limitations brought about by traditional manual-based fabrication methods. AM has come a long way since its advent in the late 20th century. Recent advancements in AM technology have shown its potential to revolutionize the production of structural and functional HPP parts, which are of great value, especially in expanding their applications in the oil and gas industry. ${ }^{[4,6,58]}$

\section{Polysulfone}

One of the main limitations encountered by conventional fabrication techniques when producing polymers is their thermal processability. Polymers either thermally degrade easily or, for the case of some HPPs, require higher processing temperatures. Miao et al. ${ }^{[59]}$ fabricated PSU and PSU/polyaniline (PANI) composite materials via solvent-cast $3 \mathrm{D}$ printing without thermally degrading or subjecting the polymers to high-temperature processing. PSU has a relatively high $T_{\mathrm{g}}$, while PANI can thermally degrade even before it melts. ${ }^{[60]}$ This technique utilizes the extrusion of a polymeric solution out of the nozzle, which dries up and solidifies to its desired form upon evaporation of the solvent. The solution is designed to have a viscosity high enough to hold its shape and rapidly dries up after extrusion process. Different concentrations of PSU and PSU/PANI solvent-based inks were produced by dissolving in a mixed

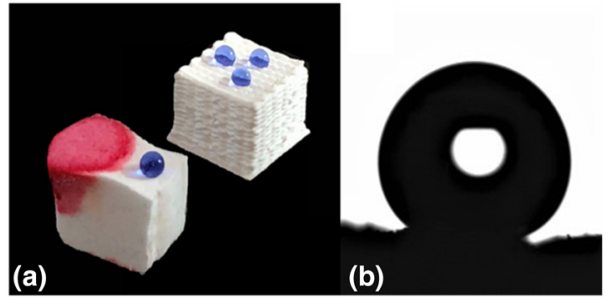

(c)
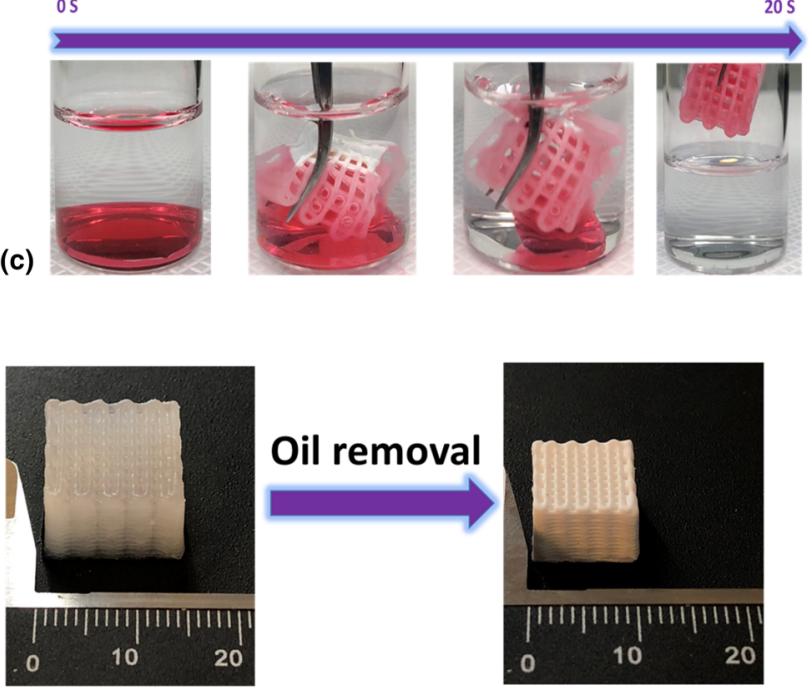

(d)
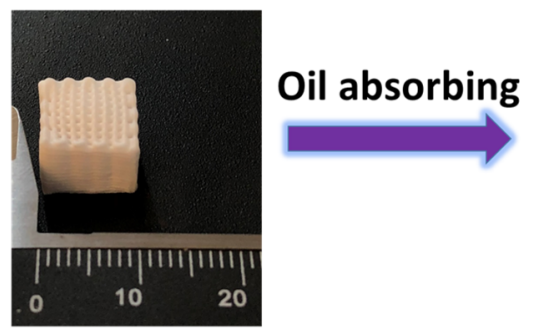

(e)

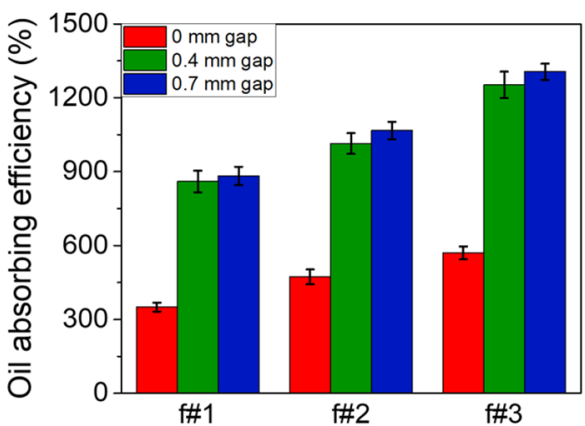

(f)

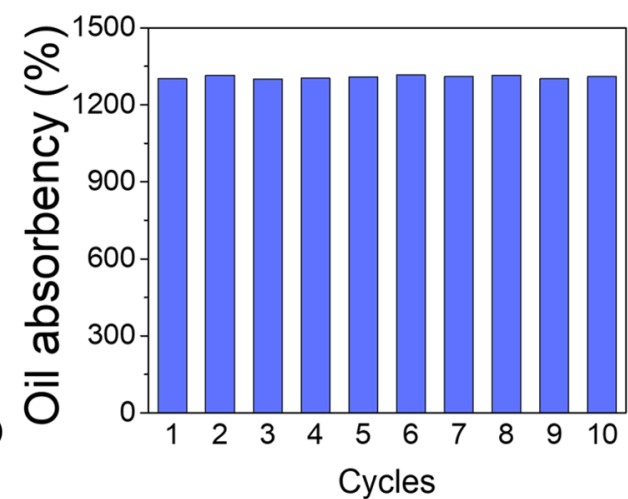

Figure 4. A hierarchical porous silicone was 3D printed by the Advincula group to demonstrate superhydrophobicity/superoleophilicity for oil-water separation: A-B) superhydrophobic contact angle and oil (red) absorption, C) model oil absorption-methylene chloride (red) in water, D) oil absorbency and size change, E) \% swelling with oil absorbency and size of opening, and F) cyclic repeatability and retention of swelling up to 10 cycles. ${ }^{[45]}$ Reprinted (adapted) from Ref. 45 with permission from Wiley. 
mrs Communications

Table II. Other applications of 3d-printed polymers for the oil and gas industry.

\begin{tabular}{|c|c|c|c|c|}
\hline Application & 3D-printed part & $3 \mathrm{D}$ printing technology & Material & References \\
\hline Volatile organic compound (VOC) removal & Filter & FFF & ABS & {$[52]$} \\
\hline Oil storage/self-lubrication & $\begin{array}{l}\text { Porous polyimide } \\
\text { (PI) material }\end{array}$ & Direct ink writing & PI & {$[53]$} \\
\hline Petroleomic studies & Microfluidic & FDM & PETG & {$[54]$} \\
\hline Foam flow/displacement & Porous medium & Polyjet & Acrylic-based material & {$[55]$} \\
\hline Production of biodiesel from (FFA)-free oils & Rotor & FFF & ABS & {$[56]$} \\
\hline Subsea well stimulation and acid treatments & Hydraulic line & FFF & PEEK composite & [57] \\
\hline
\end{tabular}

dicholoromethane (DCM) and dimethtlyformamide (DMF) solvents, with dichloroethane (DCE) as a binder. Via direct write deposition, the PSU and PSU/PANI composites were found to be printable even at room temperature. Results also showed that the use of undoped PANI produced nonconductive parts, while incorporating doped PANI in the solvent-based ink resulted in conductive printed parts. These 3D-printed PSUbased composites are useful for static dissipation and other electrical applications. Furthermore, the versatility of solventcast direct write deposition to process polymers from solutions enables a variety of ways to combine materials and produce a composite ink that can be used for fabricating 3D-printed parts with improved properties.

PSU also possess remarkable properties such as high impact resistance, high flexural modulus, and exceptional stability in high-temperature and high-pressure environments. ${ }^{[61]}$ Additionally, PSU is reported to possess better permeability, and good corrosion and fouling resistance, ${ }^{[62,63]}$ all of which can be beneficial if used as membranes for $\mathrm{H}_{2}, \mathrm{NH}_{3}$, and other refinery gases, and ultrafiltration for water and hydrocarbon purification. Several studies have also reported methods for improving the antifouling and antimicrobial performance, and separation efficiency of PSU-based membranes by incorporating poly(amide-imide) $(\mathrm{PAI}), \mathrm{TiO}_{2}$, and $\mathrm{CuO}$ particles. ${ }^{[64-67]}$

Yuan et al. ${ }^{[47]}$ used SLS to develop a PSU membrane for oil and water separation. A superhydrophobic and superoleophilic switchable surface wettability for the printed membranes was achieved through coating of a self-assembled candle soot. The stability of the membrane's mechanical, chemical, and switchable wettability properties was evaluated by subjecting the samples to sonication, immersion in different acidic and basic solutions, and 10 cycles of switchable oil/water separation, respectively.

\section{Polyetherimide}

Studies on common polymers currently utilized in AM technologies, particularly using FDM, have reported that printed products generally have lower mechanical properties compared to those produced by conventional fabrication methods, such as extrusion or injection molding. Printed thermoplastics like ABS, nylon, and polylactic acid (PLA), having low melting temperatures of less than $280^{\circ} \mathrm{C}$, experience bending and deformation, which can be attributed to the presence of pores, poor interlayer adhesion, and shrinkage during printing and cooling. Overcoming these problems by modifying current materials or exploring new ones, can lead to enhanced mechanical properties of the printed parts. ${ }^{[68-71]}$

Polyetherimide (PEI) is a highly heat-resistant HPP with high flame retardancy, high $T_{\mathrm{g}}$, good mechanical properties, and good melt processability. ${ }^{[4,69,70,72]}$ HPPs displaying such properties are highly attractive for AM techniques (e.g., FDM), as these properties may address the challenges encountered when printing common thermoplastics.

Zaldivar and co-workers ${ }^{[68]}$ examined the influence of the print orientation on the macrostructural, thermal, and mechanical characteristics of ULTEM $\AA$, a tradename for PEI developed in 1982 by General Electric. After printing with a Stratasys FDM 400 Printer, it was found that there was a significant variation on the tensile strength, failure strain, Poisson's ratio, coefficient of thermal expansion and modulus with the build orientation of the specimens. It was also noticed that the printed parts behaved more like laminated composites than isotropic cast resins, which was suggested by their fracture surfaces.

Jiang et al. ${ }^{[69]}$ also successfully printed PEI using FDM and results showed that the optimal nozzle temperature for printing PEI is $370^{\circ} \mathrm{C}$. It was also demonstrated that printing orientation greatly affects the mechanical properties of the printed parts, with parts printed at $90^{\circ}$ orientation having the highest tensile strength. In addition, printing at different directions yielded anisotropic behavior on the material's elasticity, viscosity, and mechanical properties.

The mechanical and thermal behavior of FDM-printed ULTEM ${ }^{\circledR} 1000$ were also studied by Polyakov et al. ${ }^{[70]}$ In their work, they developed nanomodified PEI composites by incorporating vapor-grown carbon nanofibers (VGCF). With the addition of $1 \% \mathrm{VGCF}$, the tensile strength and elastic modulus of the printed materials increased from 90.1 to 97.6 $\mathrm{MPa}$ and from 2527 to $2844 \mathrm{MPa}$, respectively, both of which were attributed to a decreased in the material's porosity. However, the $T_{\mathrm{g}}$, coefficient of thermal expansion (CTE), and thermal decomposition temperature were not affected due to lack of strong adhesion between the carbon nanofibers and PEI matrix. It was also observed that the nanocomposites have no negative impact on the human fibroblasts culture, which makes the material bioinert. Moreover, the surface of 
the material displayed a good cell adhesion suitable for cell proliferation and can be utilized in biomedical applications.

The mechanical integrity of FDM-fabricated ULTEM ${ }^{\circledR}$ 9085 was further improved by McLouth et al. ${ }^{[73]}$ Atmospheric plasma treatment (APT) was employed to modify and enhance the wetting and bonding characteristics of the printed PEIs. The plasma-treated printed samples manifested a $35 \%$ increase in interfacial strength. However, overly exposed samples to APT resulted in the formation of bound ash on their surface, leading to a decrease in strength. With the abovementioned excellent properties of PEI, 3D-printed PEIs can have potential uses in the oil and gas applications as connectors, insulators, membrane materials, spacers, and structural parts. ${ }^{[74]}$

\section{Polyvinylidene fluoride}

Another potential HPP that can be of great importance in the oil and gas is polyvinylidene fluoride (PVDF). Its resistance to high temperature, tolerance to chemical attack and UV exposure, low gas and fluid permeability, high flame retardance, creep and abrasion resistance, and good strength retention at a broader temperature range make it a good candidate for structural components such as tubes and fittings. Furthermore, PVDF can be used in smart devices such as pressure or strain sensor due to its ferroelectric and piezoelectric properties. $^{[4,75,76]}$

Several groups have already reported the use of different 3D printing techniques to fabricate PVDF and its composites for a wide variety of oil and gas applications. Early reports on the AM of PVDF have focused on its piezoelectric properties, while latter ones have centered on its potential as a structural component. PVDF nanocomposites containing synthesized and modified barium titanate $\left(\mathrm{BaTiO}_{3}\right)$ nanoparticles were printed by Kim et al. ${ }^{[77]}$ using digital projection printing (DPP). The exposure from the light-supplied energy encouraged the formation of covalent bonds between the linker molecules on the modified surface of the nanoparticles and polymer matrix, which effectively transferred mechanical stress from the matrix to the piezoelectric nanoparticles. This phenomenon resulted in a much better piezoelectric performance due to enhanced mechanical-to-electrical conversion process of the nanocomposites. Kim et al. ${ }^{[78]}$ further showed that polymer blends (i.e., $2 \mathrm{wt} \% \mathrm{PVDF}$ ) with the best piezoelectric properties can be printed using SLA, a technique similar to DPP which also employs light to print the parts.

Inclusion of fillers with negative CTE such as zirconium tungstate $\mathrm{Zn}\left(\mathrm{WO}_{4}\right)_{2}$ in printing PVDF was reported by Momenzadeh and co-workers. ${ }^{[79]}$ The overall manufacturability of PVDF was improved due to the CTE decrease and unwanted distortion in printed parts. However, a substantial decrease in mechanical properties including effective yield strength and elongation to failure was observed. Interestingly, this issue may be overcome by incorporating appropriate $\mathrm{Zn}\left(\mathrm{WO}_{4}\right)_{2}$ loadings to balance dimensional tolerances without sacrificing the mechanical properties. A blend of PVDF/thermoplastic polyurethane (TPU) filled with carbon black-polypyrrole (CBPPy) filament was used by Bertolini et al. ${ }^{[80]}$ in fabricating a flexible and FDM printable conductive composite. The optimal printability, electrical, and mechanical properties of the resulting composites were achieved by optimizing the blend and filler compositions. Mullaveetil et al. ${ }^{[76]}$ investigated the outcomes of different infill patterns and overall printability on the mechanical behavior of printed PVDF-based materials (Fig. 5). Among the infill patterns tested, the greatest tensile strength was observed on the concentric pattern, while lower tensile

(a)

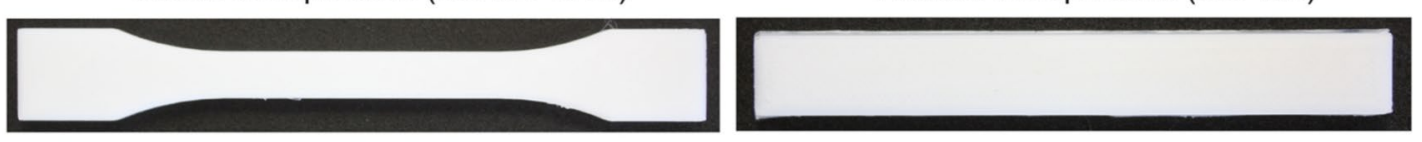

(b)
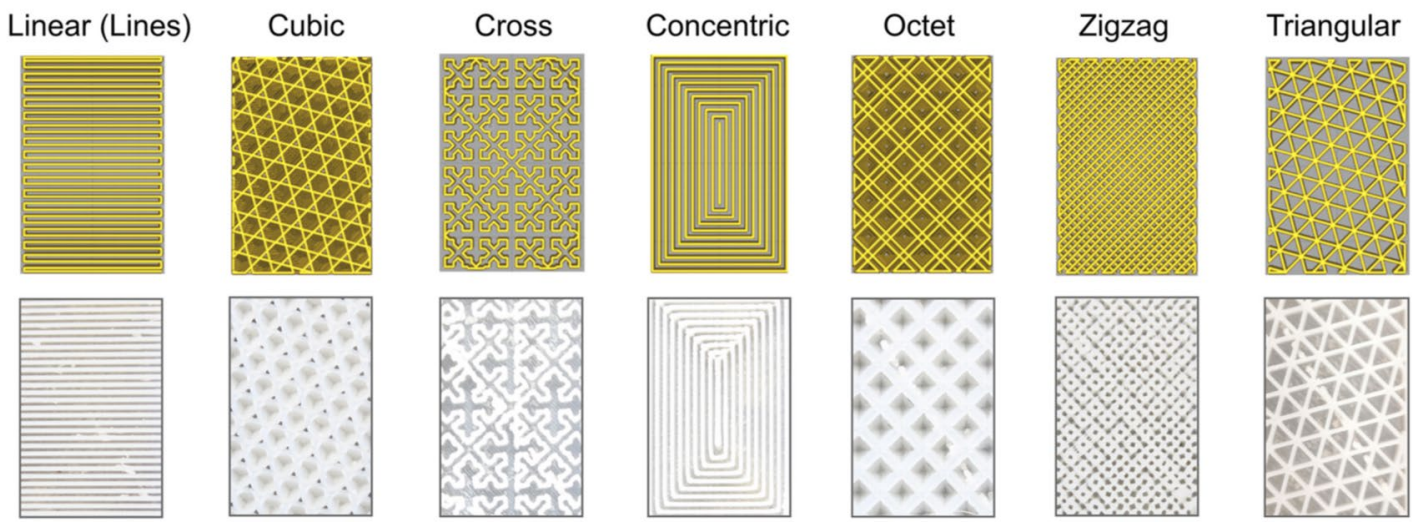

Figure 5. (a) Tensile and flexural 3D-printed PVDF-based samples. (b) Different lattice schematics (top) and printed samples (bottom) of tested infill patterns. ${ }^{[76]}$ Reprinted (adapted) from Ref. 76 with permission from Elsevier. 
strength was found on the cross and triangular patterns. The flexural properties of all printed patterns are comparable except for the linear ones. Employing relatively slower printing speeds in combination with a specialty FFF-tailored adhesive avoids distortions in printed parts. Additionally, the pattern with the most efficient printing time was found to be the cross pattern, while the triangular pattern was the least efficient.

Bodkhe et al. ${ }^{[81]}$ also demonstrated the use of solvent evaporation-assisted method in 3D printing PVDF nanocomposite structures with high dielectric and piezoelectric properties, without the need for the poling step. The nanocomposite ink with optimized rheology contained dissolved PVDF and dispersed $\mathrm{BaTiO}_{3}$ in acetone, DMF, and dimethyl sulfoxide (DMSO) and $\mathrm{BaTiO}_{3}$ nanoparticles, while the resulting fabricated self-supporting structures showed satisfactory mechanical integrity.

\section{Polyetheretherketone}

Polyetheretherketone (PEEK), another HPP, also possesses properties that are useful for different applications. PEEK can retain its excellent mechanical, chemical and dielectric properties up to a temperature of $250^{\circ} \mathrm{C}$. For oil and gas applications, it is highly important that the materials used exhibit high flame resistance, good resistance to oil and acids, good strength retention and dimensional stability, and high wear resistance, thus qualifying PEEK as an excellent candidate material. However, among the concerns encountered when using PEEK is its high cost and high processing temperature. ${ }^{[82,83]}$

The use of PEEK in AM has already been reported since the early 2000s. Aside from the abovementioned properties, PEEK also displays excellent biocompatibility and is considered as a substitute biomaterial for conventional materials used as long-term medical implants. Tan et al. ${ }^{[58]}$ employed SLS for fabricating biocomposite blends of PEEK and hydroxyapatite (HA) in hopes to address the high processing temperature for PEEK and other issues encountered with using traditional manual-based fabrication techniques. Results showed that with proper control of parameters, the utility of SLS on polymers with high melting temperatures is viable without material degradation. One of the advantages of this technique is the ease of material preparation, in which different loadings of bioactive material, HA, can be incorporated through physical mixing, resulting in a more viable material for tissue engineering scaffolding. Schmidt and co-workers ${ }^{[84]}$ investigated the effect of porosity as a function of the sintering parameters on the mechanical integrity of SLS-printed PEEK materials. The relatively low strength of printed PEEK parts was assumed to be highly influenced by the porosity of the samples and propagation of cracks guided by the borders of the particles. It was observed that the relative density of the samples can be increased by varying the laser energy input per area and using the appropriate preheating temperature, which, in turn, can also improve the mechanical integrity of the printed PEEK.

In another study, ${ }^{[85]}$ the effects of different build orientations on the dimensional accuracy, weight, and mechanical behavior of high-temperature laser-sintered (HT-LS) PEEK OPTIMA ${ }^{\circledR}$ cranial implants were also examined. Results showed that the fabricated implants with horizontal and inverted horizontal orientations (Fig. 6) were compression resistant and attained the smallest deviation from the design model. On the other hand, the design with the lowest accuracy was observed in vertically manufactured implants, which showed a 70\% less first failure compared to inverted horizontal implants.

FDM has also been extensively used to print PEEK and PEEK-based materials. Early studies have focused on the potential of printed PEEK for biomedical applications. Due to the
Figure 6. Different build orientations of HT-LS cranial implants. ${ }^{[85]}$ Reprinted (adapted) from Ref. 85 with permission from Elsevier.

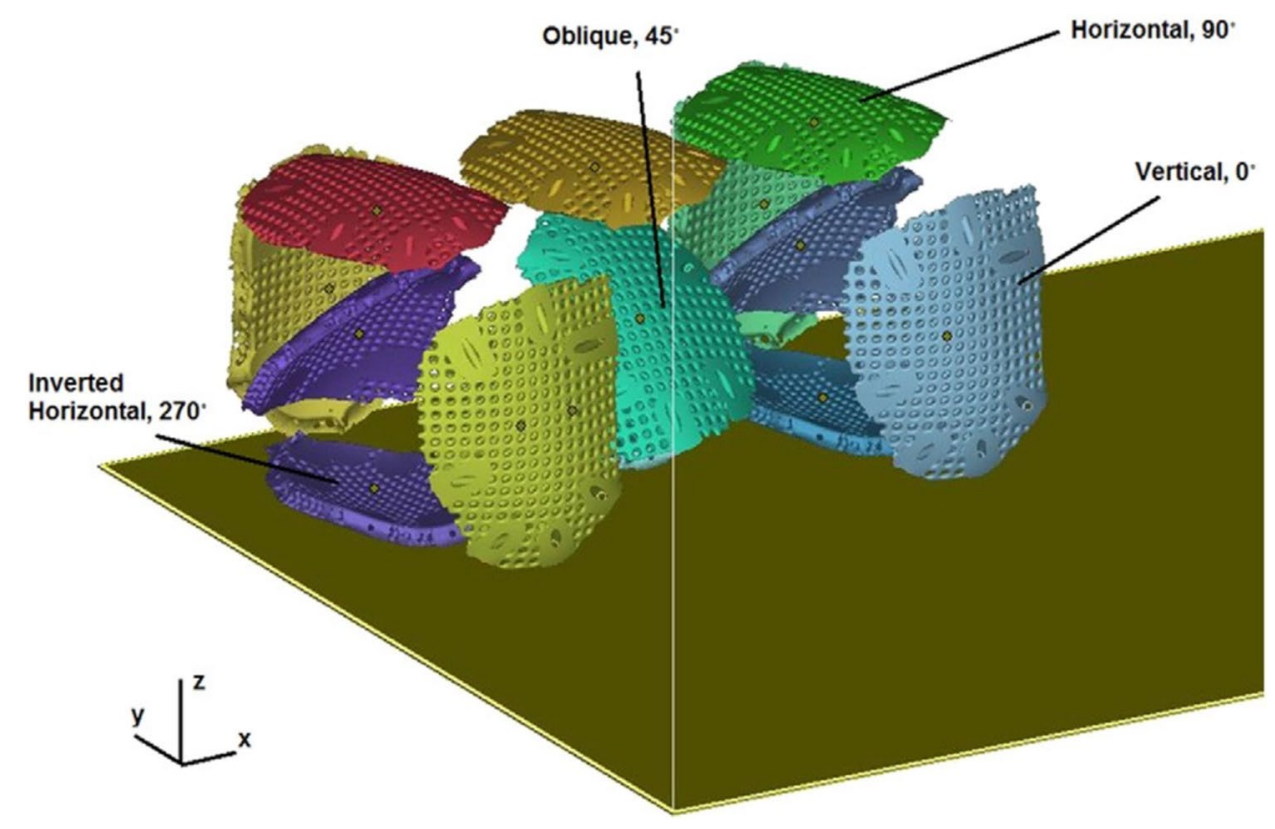


desirable properties of PEEK, much research studies in the biomedical field have shifted to FDM 3D printing of PEEK and exploring different parameters toward improvement of printed PEEK-based parts. Valentan et al. ${ }^{[86]}$ developed a specialized high-temperature FDM machine for processing PEEK. However, due to limited knowledge in this field at the time of execution of the study, they were not able to provide significant results and called for further development in the improvement of the mechanical properties of the printed parts. Vaezi et al. ${ }^{[87]} \mathrm{dem}-$ onstrated that proper heat management and heat distribution during printing can result in a successful printing of porous PEEK with promising compressive and flexural properties, not only for biomedical applications, but also for load-bearing and non-loadbearing applications. Deng et al. ${ }^{[88]}$ also developed a customized FDM system for printing PEEK, where the PEEK tensile properties were optimized by focusing on the effects of different printing parameters. Likewise, the addition of carbon fiber filler affecting the structural and thermal properties of 3D-printed PEEK-based composites (Fig. 7) was reported by Stepashkin et al., ${ }^{[89]}$ where tailoring the mechanical parts with desired anisotropic properties for specific applications was shown to be achievable with FDM 3D printing. The increasing research interests on the AM exploration for PEEK can hold promising avenues in various oil and gas applications such as bearings, piston parts, pumps, compressor plate valves, cable insulation, liners for slicklines, wirelines, drilling jars, drilling pipes, sealing, connectors, and valve seats. ${ }^{[4,90,91]}$ This progress holds a promising avenue for PEEK in various oil and gas applications.

\section{Challenges and opportunities}

The widespread use of 3D printing in the oil and gas industry is expected in the near future. However, to accelerate its industrial adoption, several issues may have to be deliberated, which

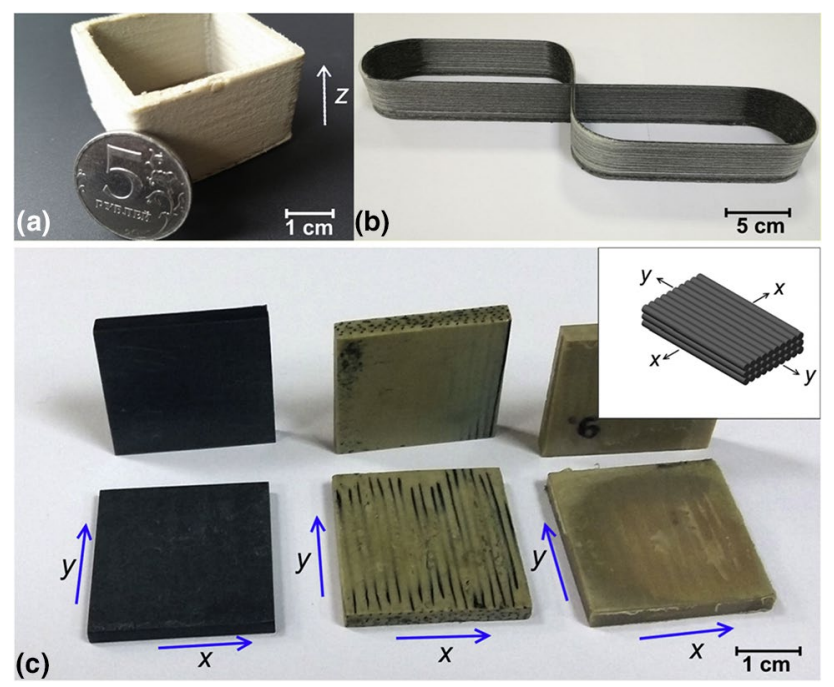

Figure 7. (a)-(c) 3D-printed PEEK with carbon fibers printed using SkolTech FDM Z2 3D printer ${ }^{[89]}$ Reprinted (adapted) from Ref. 89 with permission from Elsevier. include material properties, safety, reliability, and standards for processing and testing. The advantages of $3 \mathrm{D}$ printing over conventional (or bulk) manufacturing are its ability to quickly prototype and manufacture a limited number of complex parts (i.e., a few thousand parts). However, for mass production of parts (i.e., hundreds of thousands to millions of parts), especially those having simple designs, it is ideal to employ conventional manufacturing methods.

\section{Materials \\ Anisotropy}

Most 3D-printed parts are inherently anisotropic ${ }^{[17]}$ due to the layer-by-layer type of fabrication compared to formative and subtractive manufacturing. To overcome this issue, $3 \mathrm{D}$ printing parameters such as printing speed, printing temperature, layer height, and the like can be optimized, while other 3D printing technologies with lesser degree of anisotropy can be used.

\section{Properties}

Surface properties such as hydrophobicity and oleophilicity, which can be achieved by using different types of HPP materials with varying surface energies, should be explored to further realize the use of their 3D-printed forms in the oil and gas industry. The use of salt- and pH-resistant bio-based materials as an environment-friendly and sustainable approach for fabricating micro- and nanoscale membranes and aerogels has been advantageous in removing and recovering spilled oil from water resources. In addition, the reusability of these materials after oil removal makes them attractive and costefficient. Hence, new and affordable synthetic and bio-based materials with different printability and characteristics should be explored and combined with HPPs to achieve composite materials with synergistic properties.

\section{Post-processing}

Post-processing is the step performed after the 3D-printed parts are removed from the build plate. This step can be divided into (i) primary processes, which are done to increase the suitability of printed parts for a particular application (e.g., cleaning and support removal), and (ii) secondary post-processing, which are optional (or specialized) finishing operations employed to improve the properties, esthetics, and functionality of the printed part (e.g., vapor smoothing, painting, sanding, and the like).${ }^{[92]}$ Most 3D-printed materials require finishing or postprocessing steps, which could add up extra time and cost for production. The cost may include that for post-processing materials, use of equipment and facilities, and labor cost. ${ }^{[17]}$ Eliminating the need for post-processing or at least, reducing its cost is very important. Printing speed, print quality, capability to produce new materials, and portability are important considerations, not only for lowering the overall cost, but also for the establishment of new 3D printing technologies or improvement of existing technologies. 


\section{Development of standards and digital inventory for 3D printing}

There are still very few approved and evaluated standards by standardization organizations and certification agencies (e.g., ISO and ASTM) as standardization efforts are essentially industry driven. In order to boost the adoption of 3D printing by industries, improved technologies and innovative materials should be developed. The development of these standards ensures that the 3D-printed HPP parts live up to expectations (i.e., assurance and quality), and are reliable, sustainable, and safe to produce and use. ${ }^{[17,57]}$ Having established standards also provides a basis for fabricating 3D-printed HPP products as replacement parts and prevents untimely failure of equipment and instruments. ${ }^{[93]}$ Without these standards to guide the use of technology and ensure the performance of 3D-printed materials, the adoption of $3 \mathrm{D}$ printing by the oil and gas industry may be slow. ${ }^{[94]}$ There is also a need to promote the creation of a digital library, where different digital 3D-printed designs for parts used in the oil and gas industry can be easily accessed, thus reducing the time needed for prototyping the needed part. These digital libraries are being used in the medical field and are beneficial in expanding the adoption and use cases of 3D printing. ${ }^{[14]}$ Oil and gas companies and their suppliers can share these libraries for rapid production of spare and replacement parts. Such digital libraries are merely virtual repositories and should not incur any additional cost.

\section{D printing}

In $4 \mathrm{D}$ printing, the printed part can change shape over time in response to an external stimulus (e.g., heat, light, water, $\mathrm{pH}$, and magnetic field). In this technology, the 3D-printed parts, also called smart materials, can undergo shape change or transformation, including twisting, bending, curling, folding, expanding (linear or non-linear expansion), either from 1D, 2D, or 3D structures. ${ }^{[13]}$ Possible 4D printing applications in the oil and gas industry include pipelines capable of changing their diameter depending on the volumetric flowrate and valves or pneumatic flaps that can close or open depending on the pressure or other stimuli.

\section{Onsite printing of spare parts}

Probably, the most important industrial benefit of AM in the oil and gas sector is making the production of replacement or spare parts onsite possible. Anything from simple tools to more complex parts in the oil field and offshore facilities may be printed easily and quickly.

\section{Summary and perspectives}

In summary, this prospective outlined the potential use of 3D-printed HPPs and their expected advantages in the oil and gas industry. HPPs and their composites have been adopted in various practical and industrial applications due to their excellent chemical resistance, thermal stability, and mechanical strength. The establishment of new technologies for the oil and gas industry has always been a challenge, especially if the technology calls for the manufacturing and development of new materials. Although the adoption of 3D printing by the oil and gas industry may seem gradual, the potential benefits it can afford can be remarkable. The specifics of the oil and gas global market in the following decades imply that the necessity for the introduction of AM to the oil and gas industry is simply due to its capability to cut production costs as $3 \mathrm{D}$ printing can fabricate materials in their exact shape, producing minimal to no waste. This further leads to reduced manufacturing lead time, improved design complexity, and increased product functionality and performance, all of which create a more flexible and streamlined supply chain management. The potential long-term applications of 3D-printed HPP materials in the oil and gas industry include major chemical process equipment innovation for improved oilfield operations, heat exchanging processes, piping and refinery systems, reaction vessels, and other machinery parts. All these applications may be assessed according to where they fit in the oil and gas supply chain as illustrated in Fig. 2. The number of use cases may also be further increased by properly addressing the concerns and challenges involved in the use of 3D printable materials. Most importantly, the adoption of AM can move the oil and gas industry toward the practice of onsite and on-demand spare part fabrication.

\section{Acknowledgments}

This work is supported by the University of Tennessee, Governor's Chair Program. A portion of this work is also funded by the Department of Energy's Kansas City National Security Campus (RAV and ZJS), operated by Honeywell Federal Manufacturing \& Technologies, LLC under contract number DE-NA0002839. Disclaimer: The Department of Energy's Kansas City National Security Campus is operated and managed by Honeywell Federal Manufacturing \& Technologies, LLC under contract number DE-NA0002839. This work is also supported by the Department of Science and Technology_-Philippine Council for Industry, Energy, and Emerging Technology Research and Development (DOST-PCIEERD) for JRCD and VJG, Bataan Peninsula State University for JRCD, and University of the Philippines Diliman for VJG.

\section{Declarations}

\section{Conflict of interest}

On behalf of all authors, the corresponding author states that there is no conflict of interest.

\section{References}

1. A. Inkpen, M.H. Moffett, The Global Oil \& Gas Industry: Management, Strategy and Finance (PennWell Books, LLC, Tusla, 2011) 
2. IBISWorld: Global oil \& gas exploration \& production market size 20052025, 2021. https://www.ibisworld.com/global/market-size/global-oilgas-exploration-production/. Accessed 04 Aug 2021.

3. R. C. Advincula: 3D printing high performance polymers and the oil and gas industry. Corrosion 2019. in (OnePetro, 2019).

4. A.C.C. De Leon, Í.G. da Silva, K.D. Pangilinan, Q. Chen, E.B. Caldona, R.C. Advincula, High performance polymers for oil and gas applications. React. Funct. Polym. 162, 104878 (2021)

5. E.B. Caldona, A.C.C. De Leon, B.B. Pajarito, R.C. Advincula, A review on rubber-enhanced polymeric materials. Polym. Rev. 57(2), 311 (2017)

6. A.C. de Leon, Q. Chen, N.B. Palaganas, J.O. Palaganas, J. Manapat, R.C. Advincula, High performance polymer nanocomposites for additive manufacturing applications. React. Funct. Polym. 103, 141 (2016)

7. J. A. Camisa, V. Verma, D. 0. Marler, A. Madlinger, Additive manufacturing and $3 \mathrm{D}$ printing for oil and gas-transformative potential and technology constraints. The Twenty-fourth International Ocean and Polar Engineering Conference. in (OnePetro, 2014).

8. L. Vendra, A. Achanta, Metal additive manufacturing in the oil and gas industry. Solid Free. Fabr. 7, 454 (2018)

9. M. Sireesha, J. Lee, A.S.K. Kiran, V.J. Babu, B.B. Kee, S. Ramakrishna, A review on additive manufacturing and its way into the oil and gas industry. RSC Adv. 8(40), 22460 (2018)

10. R.C. Advincula, J.R.C. Dizon, E.B. Caldona, R.A. Viers, F.D.C. Siacor, R.D. Maalihan, A.H. Espera Jr., On the progress of 3D-printed hydrogels for tissue engineering. MRS Commun. 11, 539 (2021). https://doi.org/10. 1557/s43579-021-00069-1

11. F.D.C. Siacor, Q. Chen, J.Y. Zhao, L. Han, A.D. Valino, E.B. Taboada, E.B. Caldona, R.C. Advincula, On the additive manufacturing ( $3 \mathrm{D}$ printing) of viscoelastic materials and flow behavior: from composites to food manufacturing. Addit. Manuf. 45, 102043 (2021)

12. D.B. Gutierrez, E.B. Caldona, R.D. Espiritu, R.C. Advincula, The potential of additively manufactured membranes for selective separation and capture of C02. MRS Commun. 11, 391 (2021). https://doi.org/10.1557/ s43579-021-00062-8

13. L.D. Tijing, J.R.C. Dizon, I. Ibrahim, A.R.N. Nisay, H.K. Shon, R.C. Advincula, 3D printing for membrane separation, desalination and water treatment. Appl. Mater. Today 18, 100486 (2020)

14. R.C. Advincula, J.R.C. Dizon, Q. Chen, I. Niu, J. Chung, L. Kilpatrick, R. Newman, Additive manufacturing for COVID-19: devices, materials, prospects, and challenges. MRS Commun. 10(3), 413 (2020)

15. A.D. Valino, J.R.C. Dizon, A.H. Espera Jr., Q. Chen, J. Messman, R.C. Advincula, Advances in 3D printing of thermoplastic polymer composites and nanocomposites. Prog. Polym. Sci. 98, 101162 (2019)

16. J.R.H.S. Agueda, Q. Chen, R.D. Maalihan, J. Ren, Í.G. da Silva, N.P. Dugos, E.B. Caldona, R.C. Advincula, 3D printing of biomedically relevant polymer materials and biocompatibility. MRS Commun. 11, 197 (2021). https:// doi.org/10.1557/s43579-021-00038-8

17. J.R.C. Dizon, A.H. Espera Jr., Q. Chen, R.C. Advincula, Mechanical characterization of 3D-printed polymers. Addit. Manuf. 20, 44 (2018)

18. A.H. Espera, J.R.C. Dizon, Q. Chen, R.C. Advincula, 3D-printing and advanced manufacturing for electronics. Prog. Addit. Manuf. 4, 245-267 (2019)

19. P.M. Hergenrother, The use, design, synthesis, and properties of high performance/high temperature polymers: an overview. High Perform. Polym. 15(1), 3 (2003)

20. 3DXTECH: Thermax PPS [Polyphenylene Sulfide], 2021. https://www. 3dxtech.com/product/thermax-pps/. Accessed 04 Aug 2021.

21. 3DXTECH: Thermax PEI made using ULTEM 9085 [Certified], 2021. https:// www.3dxtech.com/product/thermax-pei-using-ultem-9085/. Accessed 04 Aug 2021.

22. 3DXTECH: Thermax PEl made using Ultem 1010 [Certified], 2021. https:// www.3dxtech.com/product/thermax-pei-using-ultem-1010/. Accessed 04 Aug 2021.

23. 3DXTECH: Thermax PEEK, 2021. https://www.3dxtech.com/product/therm ax-peek/?attribute_pa_diameter $=1-75 \mathrm{~mm} \&$ attribute_pa_weight $=250 \mathrm{~g} \&$ attribute_pa_color=natural. Accessed 04 Aug 2021.

24. MakeltFrom.com: Polyphenylsulfone (PPSU), 2020. https://www.makei tfrom.com/material-properties/Polyphenylsulfone-PPSU. Accessed 04 Aug 2021.
25. Matmatch: Polytetrafluoroethylene (PTFE): Properties, Processing, and Applications, 2021. https://matmatch.com/learn/material/polytetrafluoro ethylene-ptfe-teflon. Accessed 04 Aug 2021.

26. Omnexus: Polyvinylidene Fluoride (PVDF): Complete Guide, 2021. https:// www.omnexus.specialchem.com/selection-guide/polyvinylidene-fluor ide-pvdf-plastic. Accessed 04 Aug 2021.

27. E.B. Caldona, D.W. Smith, D.0. Wipf, Protective action of semi-fluorinated perfluorocyclobutyl polymer coatings against corrosion of mild steel. J. Mater. Sci. 55(4), 1796 (2020)

28. E.B. Caldona, E.I. Borrego, K.E. Shelar, K.M. Mukeba, D.W. Smith, Ringforming polymerization toward perfluorocyclobutyl and ortho-diynylarene-derived materials: from synthesis to practical applications. Materials 14(6), 1486 (2021)

29. E.B. Caldona, M. Zhang, G. Liang, T.K. Hollis, C.E. Webster, D.W. Smith Jr., D.0. Wipf, Corrosion inhibition of mild steel in acidic medium by simple azole-based aromatic compounds. J. Electroanal. Chem. 880, 114858 (2021)

30. E.B. Caldona, H.O. Brown, D.W. Smith Jr., D.O. Wipf, Superhydrophobic/ superoleophilic surfaces by electroless nanoparticle deposition and perfluorinated polymer modification. Ind. Eng. Chem. Res. 60(39), 14239 (2021)

31. I. Astm, ASTM52900-15 standard terminology for additive manufacturing-general principles-terminology. ASTM Int. West Conshohocken PA 3(4), 5 (2015)

32. C.J.C. Nocheseda, F.P. Liza, K.A.M. Collera, E.B. Caldona, R.C. Advincula, 3D printing of metals using biodegradable cellulose hydrogel inks. Addit. Manuf. 48, 102380 (2021). https://doi.org/10.1016/j.addma.2021. 102380

33. J.R.C. Dizon, Q. Chen, A.D. Valino, R.C. Advincula, Thermo-mechanical and swelling properties of three-dimensional-printed poly (ethylene glycol) diacrylate/silica nanocomposites. MRS Commun. 9(1), 209 (2019)

34. E.B. Caldona, D.O. Wipf, D.W. Smith Jr., Characterization of a tetrafunctional epoxy-amine coating for corrosion protection of mild steel. Prog. Org. Coat. 151, 106045 (2021)

35. R.D. Maalihan, Q. Chen, J.R.H.S. Agueda, B.B. Pajarito, H. Tamura, R.C. Advincula, On the use of surfactant-complexed chitosan for toughening 3D printed polymethacrylate composites. Macromol. Mater. Eng. 306(1), 2000448 (2021)

36. C.M. Chima, Supply-chain management issues in the oil and gas industry. J. Bus. Econ. Res. JBER (2007). https://doi.org/10.19030/jber.v5i6.2552

37. Lux Research: Oil and gas industry turning towards $3 \mathrm{~d}$ printing to cut costs and raise efficiencies, 2016. https://www.luxresearchinc.com/ press-releases/oil-and-gas-industry-turning-towards-3d-printing-tocut-costs-and-raise-efficiencies. Accessed 04 Aug 2021.

38. Z. Jiang, L.D. Tijing, A. Amarjargal, C.H. Park, K.-J. An, H.K. Shon, C.S. Kim, Removal of oil from water using magnetic bicomponent composite nanofibers fabricated by electrospinning. Composite B 77, 311 (2015)

39. E.B. Caldona, A.C.C. De Leon, P.G. Thomas, D.F. Naylor III., B.B. Pajarito, R.C. Advincula, Superhydrophobic rubber-modified polybenzoxazine/ $/ \mathrm{Si}_{2}$ nanocomposite coating with anticorrosion, anti-ice, and superoleophilicity properties. Ind. Eng. Chem. Res. 56(6), 1485 (2017)

40. E.B. Caldona, J.M.C. Albayalde, A.M.P. Aglosolos, K.S. Bautista, M.D. Tavora, S.A.P. Cabalza, J.R.O. Diaz, M.D. Mulato, Titania-containing recycled polypropylene surfaces with photo-induced reversible switching wettability. J. Polym. Environ. 27(7), 1564 (2019)

41. E.B. Caldona, J.W. Sibaen, C.B. Tactay, S.L.D. Mendiola, C.B. Abance, M.P. Añes, F.D.D. Serrano, M.M.S. De Guzman, Preparation of spray-coated surfaces from green-formulated superhydrophobic coatings. SN Appl. Sci. 1(12), 1657 (2019)

42. X. Li, H. Shan, W. Zhang, B. Li, 3D printed robust superhydrophilic and underwater superoleophobic composite membrane for high efficient oil/ water separation. Sep. Purif. Technol. 237, 116324 (2020)

43. J. Lv, Z. Gong, Z. He, J. Yang, Y. Chen, C. Tang, Y. Liu, M. Fan, W.-M. Lau, 3D printing of a mechanically durable superhydrophobic porous membrane for oil-water separation. J. Mater. Chem. A 5(24), 12435 (2017)

44. J.H. Shin, J.-H. Heo, S. Jeon, J.H. Park, S. Kim, H.-W. Kang, Bio-inspired hollow PDMS sponge for enhanced oil-water separation. J. Hazard. Mater. 365, 494 (2019) 
45. Q. Chen, J. Zhao, J. Ren, L. Rong, P.-F. Cao, R.C. Advincula, 3D Printed multifunctional, hyperelastic silicone rubber foam. Adv. Funct. Mater. 29, 1900469 (2019)

46. R. Xing, B. Yang, R. Huang, W. Qi, R. Su, B.P. Binks, Z. He, Three-dimensionally printed bioinspired superhydrophobic packings for oil-in-water emulsion separation. Langmuir 35(39), 12799 (2019)

47. S. Yuan, D. Strobbe, J.-P. Kruth, P. Van Puyvelde, B. Van der Bruggen, Super-hydrophobic 3D printed polysulfone membranes with a switchable wettability by self-assembled candle soot for efficient gravity-driven oil/ water separation. J. Mater. Chem. A 5(48), 25401 (2017)

48. C. Yan, Z. Ji, S. Ma, X. Wang, F. Zhou, 3D printing as feasible platform for on-site building oil-skimmer for oil collection from spills. Adv. Mater. Interfaces 3(13), 1600015 (2016)

49. Y. Yang, X. Li, X. Zheng, Z. Chen, Q. Zhou, Y. Chen, 3D-printed biomimetic super-hydrophobic structure for microdroplet manipulation and oil/water separation. Adv. Mater. 30(9), 1704912 (2018)

50. S. Yuan, J. Zhu, Y. Li, Y. Zhao, J. Li, P. Van Puyvelde, B. Van der Bruggen, Structure architecture of micro/nanoscale ZIF-L on a 3D printed membrane for a superhydrophobic and underwater superoleophobic surface. J. Mater. Chem. A 7(6), 2723 (2019)

51. A. Al-Shimmery, S. Mazinani, J. Flynn, J. Chew, D. Mattia, 3D printed porous contactors for enhanced oil droplet coalescence. J. Membr. Sci. 590, 117274 (2019)

52. I. Pellejero, F. Almazán, M. Lafuente, M.A. Urbiztondo, M. Drobek, M. Bechelany, A. Julbe, L.M. Gandía, Functionalization of 3D printed ABS filters with MOF for toxic gas removal. J. Ind. Eng. Chem. 89, 194 (2020)

53. C. Yang, P. Jiang, H. Qin, X. Wang, Q. Wang, 3D printing of porous polyimide for high-performance oil impregnated self-lubricating. Tribol. Int. 160, 107009 (2021)

54. J.E.B. Castiblanco, R.F. Quero, A.M. de Oliveira, D.P. de Jesus, L.W. Hantao, Improving selective channel occlusion of complex hydrocarbons and fatty acid methyl esters in urea crystals by using an expendable 3D-printed microfluidic device for sample preparation in untargeted petroleomics. Anal. Chim. Acta 1160, 338425 (2021)

55. K. Osei-Bonsu, P. Grassia, N. Shokri, Investigation of foam flow in a 3D printed porous medium in the presence of oil. J. Colloid Interface Sci. 490, $850(2017)$

56. Y.M. 00, G. Prateepchaikul, K. Somnuk, Continuous acid-catalyzed esterification using a 3D printed rotor-stator hydrodynamic cavitation reactor reduces free fatty acid content in mixed crude palm oil. Ultrason. Sonochem. 72, 105419 (2021)

57. T. Jacobs, 3D printing in the oil field kicks into production mode. J. Pet. Technol. 68(08), 30 (2016)

58. K. Tan, C. Chua, K. Leong, C. Cheah, P. Cheang, M.A. Bakar, S. Cha, Scaffold development using selective laser sintering of polyetheretherketonehydroxyapatite biocomposite blends. Biomaterials 24(18), 3115 (2003)

59. Z. Miao, J. Seo, M.A. Hickner, Solvent-cast 3D printing of polysulfone and polyaniline composites. Polymer 152, 18 (2018)

60. E.B. Caldona, C. Al Christopher, B.B. Pajarito, R.C. Advincula, Novel anticorrosion coatings from rubber-modified polybenzoxazine-based polyaniline composites. Appl. Surf. Sci. 422, 162 (2017)

61. P. Machado, A. Habert, C. Borges, Membrane formation mechanism based on precipitation kinetics and membrane morphology: flat and hollow fiber polysulfone membranes. J. Membr. Sci. 155(2), 171 (1999)

62. Prospector: Polysulfone (PSU) Typical Properties Generic PAS-Glass Fiber, 2021. https://plastics.ulprospector.com/generics/44/c/t/polys ulfone-psu-properties-processing. Accessed 04 Aug 2021

63. Solvay: Udel® PSU Polysulfone-Solvay, 2020. https://www.solvay.com/ en/brands/udel-psu. Accessed 19 June 2021.

64. A. Mollahosseini, A. Rahimpour, Interfacially polymerized thin film nanofiltration membranes on Ti02 coated polysulfone substrate. J. Ind. Eng. Chem. 20(4), 1261 (2014)

65. S. Rajesh, S. Senthilkumar, A. Jayalakshmi, M. Nirmala, A. Ismail, D. Mohan, Preparation and performance evaluation of poly (amide-imide) and Ti02 nanoparticles impregnated polysulfone nanofiltration membranes in the removal of humic substances. Colloids Surf. Physicochem. Eng. Asp. 418, 92 (2013)
66. Y. Xia, G.L. Han, Q.G. Zhang, Y. Gong, I. Broadwell, Q.L. Liu, Cu0-filled aminomethylated polysulfone hybrid membranes for deep desulfurization. J. Appl. Polym. Sci. 130(5), 3718 (2013)

67. J.A.L. Dulay, E.B. Caldona, A.R. Camacho, M.D.T. Espenilla, C.D. Gopez, E.A.A. Oribello, Phytoremediation of cadmium contaminated water by Hydrilla (Hydrilla verticillata). SLU Res. J. 41(1), 23 (2010)

68. R. Zaldivar, D. Witkin, T. McLouth, D. Patel, K. Schmitt, J. Nokes, Influence of processing and orientation print effects on the mechanical and thermal behavior of 3D-printed ULTEM $₫ 9085$ material. Addit. Manuf. 13, 71 (2017)

69. S. Jiang, G. Liao, D. Xu, F. Liu, W. Li, Y. Cheng, Z. Li, G. Xu, Mechanical properties analysis of polyetherimide parts fabricated by fused deposition modeling. High Perform. Polym. 31(1), 97 (2019)

70. I. Polyakov, G. Vaganov, V. Yudin, N. Smirnova, E. Ivan'kova, E. Popova, Study of polyetherimide and its nanocomposite 3D printed samples for biomedical application. Polym. Sci. Ser. A 62(4), 337 (2020)

71. O.S. Carneiro, A. Silva, R. Gomes, Fused deposition modeling with polypropylene. Mater. Des. 83, 768 (2015)

72. J. Ling, W. Zhai, W. Feng, B. Shen, J. Zhang, W.G. Zheng, Facile preparation of lightweight microcellular polyetherimide/graphene composite foams for electromagnetic interference shielding. ACS Appl. Mater. Interfaces 5(7), 2677 (2013)

73. T.D. McLouth, S.M. Gustafson, H.I. Kim, R.J. Zaldivar, Enhancement of FDM ULTEM $® 9085$ bond strength via atmospheric plasma treatment. $J$. Manuf. Process. 66, 179 (2021)

74. Sabic: Sabic ULTEM ${ }^{T M}$ RESIN, 2020. https://www.sabic.com/en/produ cts/specialties/ultem-resins/ultem-resin. Accessed 04 Aug 2021.

75. B. Ameduri, From vinylidene fluoride (VDF) to the applications of VDFcontaining polymers and copolymers: recent developments and future trends. Chem. Rev. 109(12), 6632 (2009)

76. F.N. Mullaveettil, R. Dauksevicius, Y. Wakjira, Strength and elastic properties of 3D printed PVDF-based parts for lightweight biomedical applications. J. Mech. Behav. Biomed. Mater. 120, 104603 (2021)

77. K. Kim, W. Zhu, X. Qu, C. Aaronson, W.R. McCall, S. Chen, D.J. Sirbuly, 3D optical printing of piezoelectric nanoparticle-polymer composite materials. ACS Nano 8(10), 9799 (2014)

78. H. Kim, L.C.D. Manriquez, M.T. Islam, L.A. Chavez, J.E. Regis, M.A. Ahsan, J.C. Noveron, T.-L.B. Tseng, Y. Lin, 3D printing of polyvinylidene fluoride/ photopolymer resin blends for piezoelectric pressure sensing application using the stereolithography technique. MRS Commun. 9(3), 1115 (2019)

79. N. Momenzadeh, H. Miyanaji, T.A. Berfield, Influences of zirconium tungstate additives on characteristics of polyvinylidene fluoride (PVDF) components fabricated via material extrusion additive manufacturing process. Int. J. Adv. Manuf. Technol. 103(9), 4713 (2019)

80. M.C. Bertolini, S. Dul, G.M. Barra, A. Pegoretti, Poly (vinylidene fluoride)/ thermoplastic polyurethane flexible and 3D printable conductive composites. J. Appl. Polym. Sci. 138(17), 50305 (2021)

81. S. Bodkhe, G. Turcot, F.P. Gosselin, D. Therriault, One-step solvent evaporation-assisted 3D printing of piezoelectric PVDF nanocomposite structures. ACS Appl. Mater. Interfaces 9(24), 20833 (2017)

82. A. Murari, A. Barzon, Comparison of new PEEK@ seals with traditional helicoflex for ultra high vacuum applications. Vacuum 72(3), 327 (2003)

83. P. Patel, T.R. Hull, R.W. McCabe, D. Flath, J. Grasmeder, M. Percy, Mechanism of thermal decomposition of poly (ether ether ketone)(PEEK) from a review of decomposition studies. Polym. Degrad. Stab. 95(5), 709 (2010)

84. M. Schmidt, D. Pohle, T. Rechtenwald, Selective laser sintering of PEEK. CIRP Ann. 56(1), 205 (2007)

85. S. Berretta, K. Evans, 0. Ghita, Additive manufacture of PEEK cranial implants: manufacturing considerations versus accuracy and mechanical performance. Mater. Des. 139, 141 (2018)

86. B. Valentan, Ž Kadivnik, T. Brajlih, A. Anderson, I. Drstvenšek, Processing poly (ether etherketone) an a $3 \mathrm{D}$ printer for thermoplastic modelling. Mater. Tehnol. 47(6), 715 (2013)

87. M. Vaezi, S. Yang, Extrusion-based additive manufacturing of PEEK for biomedical applications. Virtual Phys. Prototyp. 10(3), 123 (2015)

88. X. Deng, Z. Zeng, B. Peng, S. Yan, W. Ke, Mechanical properties optimization of poly-ether-ether-ketone via fused deposition modeling. Materials 11(2), 216 (2018) 
89. A. Stepashkin, D. Chukov, F. Senatov, A. Salimon, A. Korsunsky, S. Kaloshkin, 3D-printed PEEK-carbon fiber (CF) composites: structure and thermal properties. Compos. Sci. Technol. 164, 319 (2018)

90. Western Falcon, Falcon Ultratube ${ }^{\mathrm{TM}}$ Thermoplastic Liner, 2020. https:// westernfalcon.com/ultratube/. Accessed 27 0ct 2021.

91. P. Lan, J.L. Meyer, B. Vaezian, A.A. Polycarpou, Advanced polymeric coatings for tilting pad bearings with application in the oil and gas industry. Wear 354, 10 (2016)
92. J.R.C. Dizon, C.C.L. Gache, H.M.S. Cascolan, L.T. Cancino, R.C. Advincula, Post-processing of 3D-printed polymers. Technologies 9(3), 61 (2021)

93. B.0. Omiyale, P.K. Farayibi, Additive manufacturing in the oil and gas industries-a review. Analecta Tech. Szeged. 14(1), 9 (2020)

94. M. Burns, and C. Wangenheim, Metal 3D printing applications in the oil $\&$ gas industry. SPE Middle East Oil and Gas Show and Conference. in (OnePetro, 2019). 